\title{
Effect of Frequency of Uniform and Disturbed Pulsatility Flow on Tissue Factor Expression of Human Umbilical Vein Endothelial Cells
}

\author{
Takeshi Moriguchi ${ }^{1,2}$, Brittany N Davis ${ }^{1,2}$, Ryuzo Abe ${ }^{1}$, Mark Kidd ${ }^{1}$, and Bauer E Sumpio ${ }^{1,2 \star}$
}

${ }^{1}$ Department of Surgery, Yale University School of Medicine, 333 Cedar St, New Haven, Connecticut 06510, USA

${ }^{2}$ Veteran's Administration Connecticut Healthcare System, 950 Campbell Avenue, West Haven, Connecticut 06516, USA

\begin{abstract}
We analyzed the effect of change in frequency of uniform or disturbed pulsatile flow on human umbilical vein endothelial cells (HUVECs) in the presence or absence of thrombin (Th). We found that tissue factor (TF) RNA expression in HUVECs exposed to 60 cycles per minute (cpm) of disturbed and uniform flow was significantly higher than that induced by $30 \mathrm{cpm}$. HUVECs exposed to disturbed flow have significantly higher TF RNA expression than HUVECs exposed to uniform flow at either frequency. We conclude that frequency of pulsatile flow is a critical independent factor in TF RNA expression in HUVECs.
\end{abstract}

Keywords: Human umbilical vein endothelial cells; Shear stress; Tissue factor; Pulsatile flow; Frequency

Abbreviations: TF: Tissue Factor; HUVEC: Human Umbilical Vein Endothelial Cell; Th: Thrombin; EC: Endothelial Cell; TFF: To and Fro Flow; TFF: Pulsatile Forward Flow, PF; CPM: Cycle Per Minute

\section{Introduction}

Numerous studies demonstrate that atherosclerotic lesion development occurs at the site of the blood vessel that is subjected to disturbed flow [1-3], such as the lesser curve of the aortic arch or at bifurcations. These observations have led researchers to hypothesize that different types of blood flow have different effects on the function of endothelial cells (ECs) that line the blood vessels and are directly exposed to hemodynamic forces. The major mechanical force is fluid shear stress, the frictional force on ECs generated by blood flow. Disturbed flow occurs when the fluid shear stress is not constant in magnitude or frequency.

Recent evidence also suggests that tissue factor (TF) is abundant in atherosclerotic plaques, and its content seems to predict plaque thrombogenicity $[4,5]$. TF has been demonstrated to contribute to the hyperthrombotic state of human atherosclerotic vessels [6], and an excessive expression of TF results in an acute thrombotic event, leading to complications of atherosclerosis.

Our laboratory has investigated the role of mechanical forces on ECs [7-10], and we have previously reported a significant increase in TF expression of ECs exposed to disturbed flow $[7,11,12]$. The purpose of this study is to compare the effect of frequency of disturbed and uniform flow on EC expression of TF.

\section{Materials and Methods}

\section{Cell culture}

Primary cultures of human umbilical vein endothelial cells (HUVECs) were obtained from the laboratory of Dr Jordan Pober (Department of Pathology, Yale School of Medicine). Cells were cultured with M-199 medium enriched with $20 \%$ fetal bovine serum (FBS; Gemini Bio-Products, West Sacramento, CA), $10 \mu \mathrm{g} / \mathrm{mL}$ heparin, $50 \mu \mathrm{g} / \mathrm{mL}$ EC growth supplement (BD Biosciences, Bedford, MA), and penicillin-streptomycin antibiotic combination (both $100 \mu \mathrm{g} / \mathrm{mL}$ ), in a $5 \% \mathrm{CO}_{2}$ incubator at $37^{\circ} \mathrm{C}$. After reaching confluence, $0.25 \%$ trypsin ethylene diamine tetra acetic acid was used for detachment, and passage
2 to 4 cells were seeded on fibronection (BD Biosciences) coated glass slides $(7 \times 38 \mathrm{~mm}$ : Fisher Scientific, Pittsburgh, PA).

\section{Mechanical stress exposure}

HUVECs were exposed to shear stress, utilizing a parallel-plate flow chamber system (Cytodyne, San Diego, CA) as previously described $[7,10]$. Flow of the perfusion medium was regulated by a computercontrolled syringe pump (PHD 2000 and PHD Ultra Programmable; Harvard Apparatus, Holliston, MA). To generate pulsatile forward flow (PFF), an automated switch clamp (Auto-Fill valve box; Harvard Apparatus) is placed between the syringe pump and the flow chamber, and between the syringe pump and the culture medium reservoir. Synchronous activation of both switch clamps with the cycle allows unidirectional flow. In the to and fro flow (TFF) model, the switch clamp is not used. The flow chambers were directly attached to the flow loop circuit including the flow reservoir, which enabled culture medium in the flow chamber to be exchanged by every to-fro impulse. Approximately one-tenth of the culture media in the flow chamber was exchanged at least every $1 \mathrm{sec}$. The shear stresses were 1) 60 cycle per minute $(\mathrm{cpm})$ of PFF, i.e. a forward square wave impulse for $0.5 \mathrm{sec}$ alternating with no flow for $0.5 \mathrm{sec}, 2) 30 \mathrm{cpm}$ of PFF, i.e. a forward square wave impulse for $0.25 \mathrm{sec}$ alternating with no flow for 0.25 $\mathrm{sec}$, 3) $60 \mathrm{cpm}$ of TFF, i.e. a forward square wave impulse for $0.5 \mathrm{sec}$ alternating with a backward square wave impulse for $0.5 \mathrm{sec}$ and 4) 30 cpm of TFF, i.e. a forward square wave impulse for $0.25 \mathrm{sec}$ alternating with a backward square wave impulse for $0.25 \mathrm{sec}$. The magnitude of shear was kept constant at $14 \mathrm{dyne} / \mathrm{cm}^{2}$.

\section{Chemical stress exposure under static and flow conditions}

M199 culture medium with $1 \%$ FBS and $4 \mathrm{U} / \mathrm{mL}$ of thrombin

*Corresponding author: Bauer E Sumpio, Department of Vascular Surgery, Yale University School of Medicine, 333 Cedar St., New Haven, CT, 06520-8062, USA Tel: 1-203-785-6217; E-mail: bauer.sumpio@yale.edu

Received February 23, 2013; Accepted June 20, 2013; Published June 22, 2013 Citation: Moriguchi T, Davis BN, Abe R, Kidd M, Sumpio BE (2013) Effect of Frequency of Uniform and Disturbed Pulsatility Flow on Tissue Factor Expression of Human Umbilical Vein Endothelial Cells. J Vasc Med Surg 1: 110. doi: 10.4172/2329-6925.1000110

Copyright: (c) 2013 Moriguchi T, et al. This is an open-access article distributed under the terms of the Creative Commons Attribution License, which permits unrestricted use, distribution, and reproduction in any medium, provided the original author and source are credited. 
(Th) (Sigma-Aldrich, St. Louis, MO) was applied to HUVEC under static condition, and to HUVEC exposed to either TFF or PFF, and was present throughout the entire experiment. This dose of thrombin results in reproducible stimulation of TF expression [7,11-14]. These experiments applying mechanical and chemical stress together were performed simultaneously with the experiments applying only mechanical stress, as paired experiments.

\section{RNA isolation and measurement of TF RNA levels}

RNA was isolated using the RN easy Mini kit (Qiagen Sciences, Germantown, MD) according to the manufacturer's instruction. Two micrograms of total RNA were reverse-transcribed into cDNA using the iScript reverse transcription kit (Bio-Rad Laboratories, Hercules, CA). TF RNA levels were estimated by quantitative real-time PCR with $\beta$-actin serving as the house-keeping gene. The iQ SYBR Green Supermix (Bio-Rad Laboratories) was used in quantitative real-time PCR and all RT-PCR reactions were performed in a CFX96 Thermal Cycler machine (Bio-Rad). Primer sequences for TF were: forward 50GCC AGG AGAAAG GGG AAT-30; reverse 50-CAG TGC AAT ATA GCA TTT GCA GTA GC-30. Sequences for $\beta$-actin were: forward 50-TCA CCC ACA CTG TGC CCA TCT ACG A-30; reverse 50-CAG CGG AAC CGC TCATTG CCA ATG G -30. Primers were purchased from Integrated DNA Technologies (Coralville, IA). The Pfaffl method was used to calculate fold changes in TF mRNA expression levels [15].

\section{Statistical analysis}

The results are presented as mean \pm standard error (SEM) of at least three separate experiments. Statistical significance was determined by analysis of variance (ANOVA) followed by a post-hoc analysis of Bonferroni, or analysis of covariance (ANCOVA) when appropriate. Statistical significance was defined as $\mathrm{P}<0.05$. Statistical analysis was performed using Prism 6 for Mac OS X software package (GraphPad Software Inc., La Jolla, CA).

\section{Results}

\section{TF RNA expression induced by uniform and disturbed flow}

Figure 1 shows TF RNA expression levels in HUVECs exposed to uniform (PFF) (Figure 1A) or disturbed (TFF) flow (Figure 1B) for up to

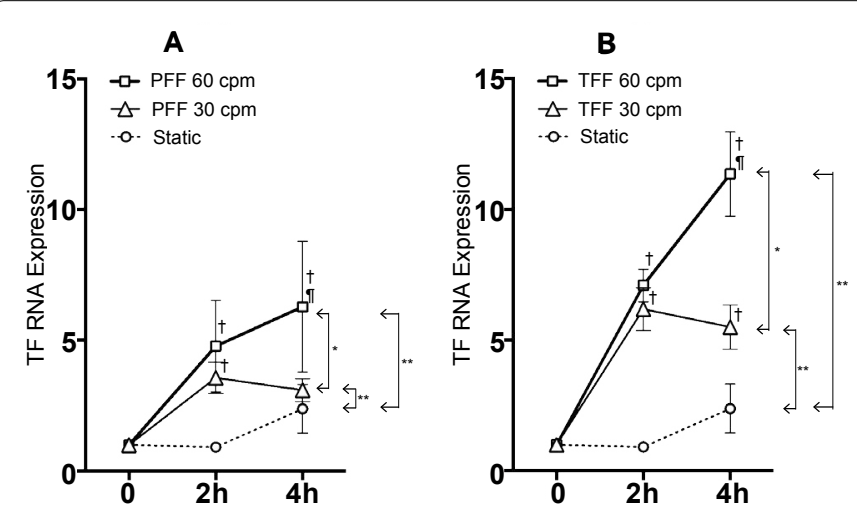

Figure 1: TF RNA expression in HUVECs exposed to PFF (Figure 1A) or TFF (Figure 1B). HUVECs were subjected to either $60 \mathrm{cpm}$ or $30 \mathrm{cpm}, 14$ dyne/ $\mathrm{cm}^{2}$ TFF or PFF for up to 4 hours. TF RNA expression was expressed as fold change compared with static control values at $0 \mathrm{~h}$ as a baseline. Values are means $\pm S E ; n=3-8$. ${ }^{*} P<0.05$, calculated by ANOVA. ${ }^{* *} P<0.05$, calculated by ANOVA, compared to static. I $P<0.05$, compared to PFF, $+P<0.05$, compared to static, calculated by post hoc analysis of Bonferoni.

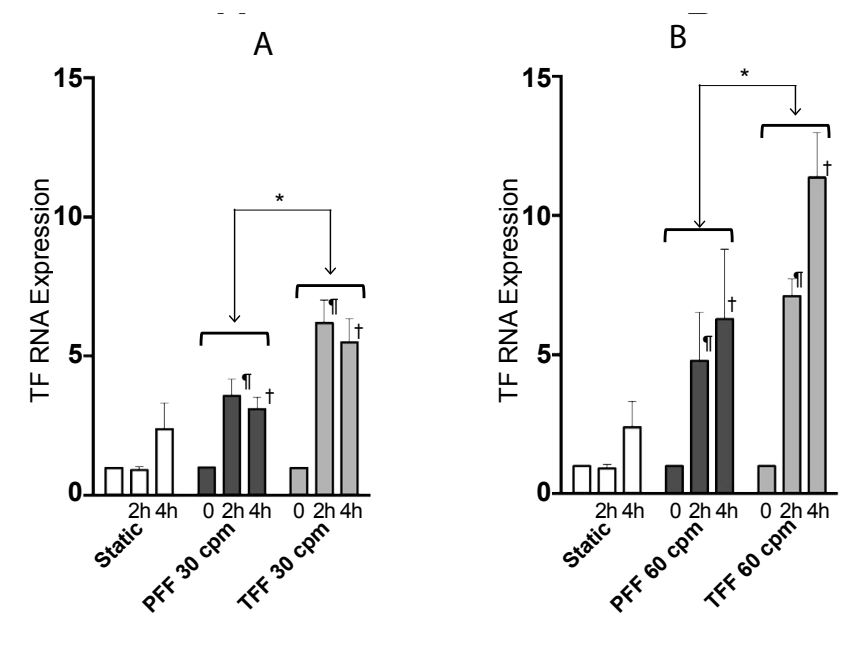

Figure 2: TF RNA expression in HUVECs exposed to $30 \mathrm{cpm}$ flow (Figure $2 A$ ) or $60 \mathrm{cpm}$ flow (Figure 2B). HUVECs were subjected to 14 dyne/cm ${ }^{2}$ TFF or PFF for up to 4 hours. TF RNA expression levels were expressed as fold change compared with static control at $0 \mathrm{~h}$ as a baseline. Values are means $\pm \mathrm{SE} ; \mathrm{n}=3-8$. ${ }^{*} \mathrm{P}<0.05$, calculated by ANOVA. TFF vs. PFF. $\mathbb{\text { II }} \dagger, \mathrm{P}<0.05$ calculated by post hoc analysis of Bonferoni.

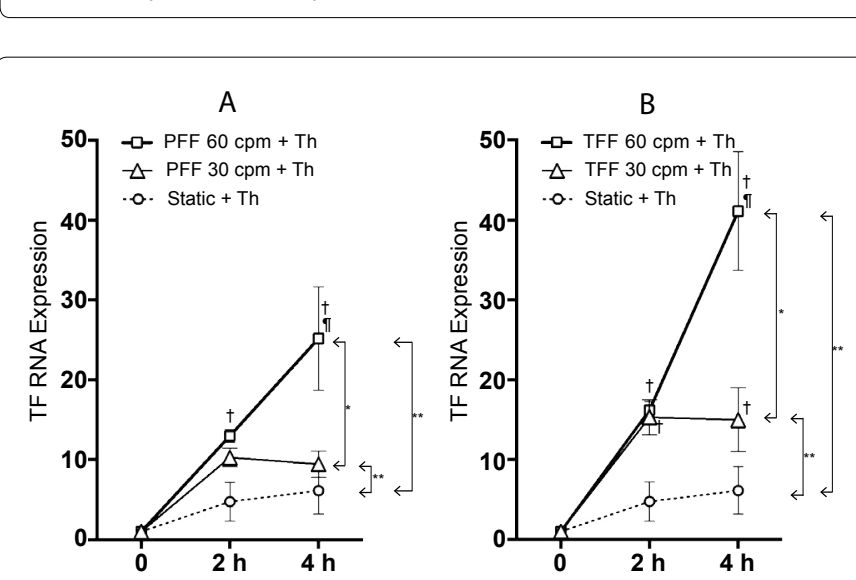

Figure 3: TF RNA expression in HUVECs exposed PFF (Figure 3A) or TFF (Figure 3B) in the presence of $4 \mathrm{U} / \mathrm{ml}$ Th. HUVECs were subjected to $60 \mathrm{cpm}$ and $30 \mathrm{cpm}, 14$ dyne $/ \mathrm{cm}^{2}$ TFF or PFF and $4 \mathrm{U} / \mathrm{ml}$ Th for up to 4 hours. TF RNA expression was expressed as fold change compared with static control at $0 \mathrm{~h}$ as a baseline. Values are means $\pm \mathrm{SE} ; \mathrm{n}=3-8$. ${ }^{*} \mathrm{P}<0.05$, calculated by ANOVA. ${ }^{* *} P<0.05$, calculated by ANOVA, compared to static. $\uparrow P<0.05$, compared to $P F F,+P<0.05$, compared to static, calculated by post hoc analysis of Bonferoni.

4 hours compared with static conditions. We have previously reported the time course of TF expression of ECs exposed to laminar flow and this started by $2 \mathrm{hr}$, peaked at $4 \mathrm{hrs}$ and then started to decline by 8 hrs. $[7,11,12]$. All mechanical stimuli conditions induced higher TF RNA expression compared with static conditions (ANOVA and posthoc analysis of Bonferroni, $\mathrm{P}<0.05)$. TF RNA expression in HUVECs exposed to $60 \mathrm{cpm}$ flow of either PFF (Figure 1A) or TFF (Figure 1B) were significantly higher than that induced by $30 \mathrm{cpm}$ (ANOVA, $\mathrm{P}<0.05)$. HUVEC exposed to TFF always had significantly higher TF RNA expression than that of HUVECs exposed to PFF with either 60 cpm or $30 \mathrm{cpm}$ (Figure 2).

TF RNA expression induced by simultaneous mechanical and chemical stimuli

Figure 3 shows TF RNA expression levels in HUVECs exposed to 
A

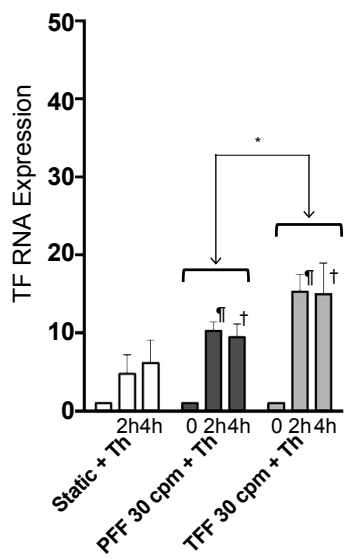

Figure 4: TF RNA expression in HUVECs exposed to $30 \mathrm{cpm}$ flow (Figure $4 \mathrm{~A}$ ) or $60 \mathrm{cpm}$ flow (Figure 4B) in the presence of $4 \mathrm{U} / \mathrm{ml}$ Th. HUVECs was subjected to 14 dyne/cm² TFF or PFF for up to 4 hours. TF RNA expression was expressed as fold change compared with static control at 0 h as base Values are means $\pm \mathrm{SE} ; \mathrm{n}=3-8 .{ }^{*} \mathrm{P}<0.05$, calculated by ANOVA. TFF vs PFF. $\mathbb{T}, \dagger, P<0.05$, calculated by post hoc analysis of Bonferoni.

both fluid flow and Th stimuli for up to 4 hours compared with static cells exposed to Th. HUVECs exposed to any mechanical stimuli and Th induced higher TF RNA expression compared with static HUVECs treated with Th (ANOVA and post-hoc analysis of Bonferroni, $\mathrm{P}<0.05)$. TF RNA expression in HUVEC exposed to $60 \mathrm{cpm}$ flow of either PFF (Figure $3 \mathrm{~A}$ ), or TFF (Figure $3 \mathrm{~B}$ ) in addition to Th were significantly higher than that induced by $30 \mathrm{cpm}$ (ANOVA, $\mathrm{P}<0.05$ ). HUVEC exposed to TFF and Th had significantly higher TF RNA expression than HUVEC exposed to PFF and Th with either frequency (Figure 4). The increase in TF RNA expression in HUVEC exposed to $60 \mathrm{cpm}$ TFF and Th (as measured by the slope between 2 and 4 hours in figure 3B) was significantly higher than that in HUVEC exposed to $30 \mathrm{cpm}$ with Th between 2 and 4 hours (ANCOVA, $\mathrm{P}<0.05$ ).

\section{Discussion}

Mechanical forces that are associated with blood flow have been shown to be major initiating factors of vascular pathology [16]. Regions of the vasculature where shear stress is low is more likely to develop atherosclerosis [17]. In addition, specific patterns of flow disturbance induced by flow separation, gradients, flow reversal and turbulence contribute to plaque formation [18].

It is now widely accepted that although there may be similar responses by EC to different hemodynamic forces, there are temporal and/or magnitude differences in these responses $[2,19,20]$. It is also now evident that sites of atherosclerosis correlate with areas of disturbed fluid dynamics and links the observations that temporal or spatial gradients in these hemodynamic forces are more potent stimuli for ECs than the actual magnitude of the force [21]. ECs exposed to unidirectional flow, especially high laminar shear, have been reported to express atheroprotective genes [2]. Low and oscillatory shear stress are closely associated with atherogenesis.

We used TFF as a model of disturbed flow because the oscillatory direction of flow change is analogous to that seen at regions high at risk for athersclerotic plaque development such as the carotid bulb. Oscillatory flow is characterized by time-averaged fluctuations in shear stress during the cardiac cycle due to forward-reverse flow cycles and disrupted flows. In this study, we specifically analyzed the effect of different frequencies of pulsatile flow, on both disturbed (TFF) and uniform flow (PFF),on TF RNA expression of HUVECs.

Our results demonstrate that although the maximum magnitude of shear and the total time that HUVECs are exposed to flow stimuli are the same, the $60 \mathrm{cpm}$ frequency induces a higher TF RNA expression than for $30 \mathrm{cpm}$ frequency. This dependence on frequency was observed in HUVECs exposed to either TFF or PFF.

The mechanism of these findings is not clear, but suggests that the EC mechanotransducer is exquisitely sensitive to spatial and temporal gradients of a mechanical force. For instance, we previously reported that an acute change in cyclic strain from $60 \mathrm{cpm}$ to $100 \mathrm{cpm}$ results in activation of $\mathrm{IP}_{3}$ [20]. In addition, an acute decrease from $100 \mathrm{cpm}$ to 60 $\mathrm{cpm}$ also resulted in an immediate increase in $\mathrm{IP}_{3}$ [19]. Bao et al. [21] demonstrated that EC exposed to different shear segments of either step flow, ramp flow, impulse flow or pulsatile shear had variable activation of signaling pathway. Likewise, we showed that bovine aortic ECs exposed to pulsatile flow frequencies of 0.5 and $1.0 \mathrm{~Hz}$, but not $1.5 \mathrm{~Hz}$, exhibited elongated morphologies and oriented with the direction of flow [22]. Our laboratory also demonstrated that $1 \mathrm{~Hz}$ but not $0.1,0.5$, or $1.5 \mathrm{~Hz}$ was optimal for bovine aortic ECs proliferation when exposed to PFF [8]. Interestingly, frequency had no effect on proliferation of bovine aortic ECs exposed to TFF [8]. Other investigators have also reported that anti-inflammatory responses of porcine aortic ECs exposed to $1 \mathrm{~Hz}$ forward flow are reversed at $2 \mathrm{~Hz}$ [23]. In addition, proinflammatory responses evoked by the $2 \mathrm{~Hz}$ but not 1 or $3 \mathrm{~Hz}$ were greater when ECs were exposed to reversing and oscillatory flow [23]. Taken together, these studies and our present results strongly suggest that the frequency of pulsatile flow is a critical independent factor in EC response to shear.

Our study also showed that TF RNA expressions at $60 \mathrm{cpm}$ in both combined stimulation of TFF and PFF with Th induces higher TF RNA expression that those of $30 \mathrm{cpm}$ with Th. Our previous report showed that there might be synergistic interaction between mechanical and chemical stimuli since the combination of mechanical and chemical stimulations yielded greater TF RNA expression levels than the theoretical values calculated by adding the results of mechanical stress alone values with chemical stress alone values [12]. The current study confirms those findings and in addition demonstrates that during simultaneous mechanical and chemical stimulation of HUVECs increasing the frequency enhanced TF RNA expression. In the cells that are subjected to disturbed flow under chemical stimuli, the reaction to the change of the frequency seems to result in a non-linear increase in TF RNA expression.TF RNA expressions of HUVECs exposed to 60 cpm TFF with Th is still increasing significantly by 4 hours, while those exposed to $30 \mathrm{cpm}$ reach peak expression by 2 hours. This is consistent with previous studies that demonstrate that, EC activated by laminar flow are down regulated over time, on the order of 1 hour. Disturbed shear, however, activates the same pathways in a sustained manner [24].

In conclusion, our study provides important information on the role of frequency of shear in the modulation of EC that are exposed to uniform or disturbed flow. This adds to our current knowledge of how flow patterns contribute to atherogenesis.

\section{Acknowledgments}

This publication was supported by grants to BES from Veterans Administration Merit Review Board.

\section{References}

1. Frangos SG, Gahtan V, Sumpio B (1999) Localization of atherosclerosis: role of hemodynamics. Arch Surg 134: 1142-1149. 
Citation: Moriguchi T, Davis BN, Abe R, Kidd M, Sumpio BE (2013) Effect of Frequency of Uniform and Disturbed Pulsatility Flow on Tissue Factor Expression of Human Umbilical Vein Endothelial Cells. J Vasc Med Surg 1: 110. doi: 10.4172/2329-6925.1000110

2. Gimbrone MA Jr, Garcia-Cardena G (2013) Vascular endothelium, hemodynamics, and the pathobiology of atherosclerosis. Cardiovasc Patho 22: $9-15$

3. Ku DN, Giddens DP, Zarins CK, Glagov S (1985) Pulsatile flow and atherosclerosis in the human carotid bifurcation. Positive correlation between plaque location and low oscillating shear stress. Arteriosclerosis 5: 293-302.

4. Crawley J, Lupu F, Westmuckett AD, Severs NJ, Kakkar VV, et al. (2000) Expression, localization, and activity of tissue factor pathway inhibitor in normal and atherosclerotic human vessels. Arterioscler Thromb Vasc Biol 20: 13621373.

5. Toschi V, Gallo R, Lettino M, Fallon JT, Gertz SD, et al. (1997) Tissue factor modulates the thrombogenicity of human atherosclerotic plaques. Circulation 95: 594-599.

6. Wilcox JN, Smith KM, Schwartz SM, Gordon D (1989) Localization of tissue factor in the normal vessel wall and in the atherosclerotic plaque. Proc Nat Acad Sci U SA 86: 2839-2843.

7. Abe R, Yamashita N, Rochier A, Abe R, Nixon A, et al. (2011) Pulsatile to-fro flow induces greater and sustained expression of tissue factor RNA in HUVEC than unidirectional laminar flow. Am J Physiol Heart Circ Physiol 300: H13451351.

8. Kadohama T, Nishimura K, Hoshino Y, Sasajima T, Sumpio BE (2007) Effects of different types of fluid shear stress on endothelial cell proliferation and survival. J Cell Physiol 212: 244-251.

9. Dardik A, Chen L, Frattini J, Asada H, Aziz F, et al. (2005) Differential effects of orbital and laminar shear stress on endothelial cells. J Vasc Surg 41: 869-880.

10. Azuma N, Akasaka N, Kito H, Ikeda M, Gahtan V, et al. (2001) Role of p38 MAP kinase in endothelial cell alignment induced by fluid shear stress. Am J Physiol Heart Circ Physiol 280: H189-197.

11. Rochier A, Nixon A, Yamashita N, Abe R, Abe R, et al. (2011) Laminar shear but not orbital shear, has a synergistic effect with thrombin stimulation on tissue factor expression in human umbilical vein endothelial cells. J Vasc Surg 54 480-488

12. Abe R, Yamashita N, Rochier A, Nixon A, Abe R, et al. (2011) Varying effects of hemodynamic forces on tissue factor RNA expression in human endothelia cells. J Surg Res 170: 150-156.
13. Zhang JJ, Kelm RJ, Biswas P, Kashgarian M, Madri JA (2007) PECAM-1 modulates thrombin-induced tissue factor expression on endothelial cells. $J$ Cell Physiol 210: 527-537.

14. Ishibashi T, Sakamoto T, Ohkawara H, Nagata K, Sugimoto K, et al. (2003) Integral role of RhoA activation in monocyte adhesion-triggered tissue factor expression in endothelial cells. Arterioscler Thromb Vasc Biol 23: 681-687.

15. Pfaffl MW (2001) A new mathematical model for relative quantification in realtime RT-PCR. Nucleic Acids Res 29: e45.

16. Gijsen F, van der Giessen A, van der Steen A, Wentzel J (2012) Shear stress and advanced atherosclerosis in human coronary arteries. J Biomech.

17. Zarins CK, Giddens DP, Bharadvaj BK, Sottiurai VS, Mabon RF, et al (1983) Carotid bifurcation atherosclerosis. Quantitative correlation of plaque localization with flow velocity profiles and wall shear stress. Circ Res 53: 502514

18. Hahn C, Schwartz MA (2009) Mechanotransduction in vascular physiology and atherogenesis. Nat Rev Mol Cell Biol 10: 53-62.

19. Brophy CM, Mills I, Rosales O, Isales C, Sumpio BE (1993) Phospholipase C: a putative mechanotransducer for endothelial cell response to acute hemodynamic changes. Biochem Biophys Res Commun 190: 576-581.

20. Rosales OR, Sumpio BE (1992) Changes in cyclic strain increase inosito trisphosphate and diacylglycerol in endothelial cells. Am J Physiol 262: C956962.

21. Bao X, Lu C, Frangos JA (2001) Mechanism of temporal gradients in shearinduced ERK $1 / 2$ activation and proliferation in endothelial cells, Am J Physio Heart Circ Physiol 281: H22-29.

22. Ito $K$, Sakamoto $N$, Ohashi T, Sato $M$ (2007) Effects of frequency of pulsatile flow on morphology and integrin expression of vascular endothelial cells, Technol Health Care 15: 91-101.

23. Himburg HA, Dowd SE, Friedman MH (2007) Frequency-dependent response of the vascular endothelium to pulsatile shear stress. Am J Physiol Heart Circ Physiol 293: H645-653.

24. Hsieh HJ, Cheng CC, Wu ST, Chiu JJ, Wung BS, et al. (1998) Increase of reactive oxygen species (ROS) in endothelial cells by shear flow and involvement of ROS in shear-induced c-fos expression. J Cell Physiol 175: 156-162. 